\title{
PERSUASIÓN GLOBAL Y ESTADO: LA UNIDAD POPULAR Y EL MUNDO
}

\author{
Joaquin Fermandois Huerta
}




\section{JOAQUÍN FERMANDOIS HUERTA}

Es licenciado en Historia por la Universidad Católica de Valparaíso (1970). Realizó sus estudios de posgrado en Alemania Federal y España y se doctoró en la Universidad de Sevilla (1984). Desde 1971 es profesor de historia contemporánea en la Pontificia Universidad Católica de Chile y desde 2019 profesor e investigador de la Universidad San Sebastián. Obtuvo la Beca Guggenheim (1989) y fue director interino del Instituto de Estudios Internacionales (1996-1998). Ha sido investigador asociado del Centro de Estudios Públicos (CEP). Sus áreas de especialidad son la historia de las relaciones internacionales, la política exterior chilena, la historia política y la historia de las ideas políticas. 


\section{PERSUASIÓN GLOBAL Y ESTADO: LA UNIDAD POPULAR Y EL MUNDO}

\section{LA IZQUIERDA EN UN SISTEMA DE ESTADOS}

El triunfo electoral de Salvador Allende, como tantos hechos en la historia, correspondía a una combinación de azar y de necesidad; lo mismo se puede decir de su desenlace final, aunque esto sea más debatible. Esto lo he desarrollado en varios ensayos recientes y en parte de un libro. La otra característica de las fuerzas que convergieron en la candidatura de Allende procedía de una tradición instalada por más de siete décadas en la sociedad chilena y correspondía a una de las posibilidades fundamentales de las persuasiones políticas modernas. Igualmente, la inmensa mayoría de los actores políticos — tomada esta expresión en un sentido amplio, referente a lo público- del país correspondían a posibilidades globales de los últimos siglos. No tiene mayor novedad para quien haya estudiado la evolución de los sistemas políticos desde el XVIII y la unificación comunicacional y, en cierta medida, de sentimientos a lo largo del planeta. Pero a la izquierda, en casi todo el mundo, le es propia una versión más estructurada de sus ideas, que se vincula más directamente y con mayor perseverancia a una sensibilidad crítica de la sociedad, bien antisistema o decididamente revolucionaria.

Con el protagonismo de las tendencias democráticas y la incorporación creciente de grupos sociales a la vida pública — en Chile, hasta mediados del siglo XX, este proceso estaba alcanzado; después solo hay recombinaciones-, se alumbró un proceso democrático en parte institucional y, a la vez, de movilización. Ello, como en tantos países, en su remoto origen partió con los "vecinos" del 18 de septiembre de 1810. Sus alcances y límites tienen que ver con un inacabable debate en torno al ser mismo de la democracia. Se producía en un país donde el sistema institucional, comparado a escala regional, en general se fue adelantando a las movilizaciones que caracterizan a la política moderna. Cuando en Chile nace la izquierda antisistema - diferente cualitativamente de las rebeldías del XIX, aunque no tan diferente en la función de "izquierda"- hacia la década de 1890, debe actuar en un país donde la política es un tema central de debate y, a pesar de la guerra civil, el sistema se halla bastante afianzado en sus estructuras. Por ello, junto a la protesta y a la limitada movilización social, debe desarrollar una estrategia más o menos forzosa de integración, algo así como una "larga marcha a través de las instituciones", experiencia común con las izquierdas en los sistemas democráticos de mejor 
funcionamiento. Esta izquierda pasaría por dos experiencias que la instalarían en el país.

Primero, que con mucho más énfasis formal que otras persuasiones políticas (por ejemplo, liberalismo y conservadurismo), se hallaba vinculada a sentimientos y racionalizaciones formalizadas con relativa coherencia y no solo a la voz de los "humillados y ofendidos", que además iban de lo más simple y sencillo, hasta lo más complejo y sofisticado, posibilitando en potencia un enorme agrupamiento social, el del entonces socialismo antisistema y de tendencia revolucionaria. Mas, ello fue multiplicado por los efectos de la revolución rusa y la subsecuente creación del comunismo, identificando a la postre por casi cuatro décadas a la misma mayoría del marxismo revolucionario con ese modelo de persuasión, instalado en Europa, América y Asia Oriental. Lo más decisivo en su relevancia es que existía un país, un sistema social, era el supuesto, donde la igualdad y la democracia directa funcionaban de manera mucho más perfecta que todo lo que se había conocido; y si existían falencias, ellas se iban a superar, ya que el futuro nació allí, era algo palpable.

Sin la revolución bolchevique aun habría existido algo así como el comunismo. Este, tanto como el fascismo, estaba delineado antes de 1914. Lo que lo potenció y cambiaría al sistema internacional hasta la Caída del Muro fue la existencia de una gran potencia que representaba con gran autoconciencia y confianza en sí misma un modelo alternativo de orden social, que rompía el orden de los estados nacionales. Sin embargo, la tendencia hacia el pluralismo de cuerpos políticos parece estar inscrita en orden de la sociedad humana, junto con la tendencia a la interacción y a elementos comunes en lo cultural, sobre todo en la creciente sociedad de masas contemporánea, comunicada con intensidad. De ahí que el orden internacional de la época de las guerras mundiales y de la Guerra Fría — a grandes rasgos entre 1917 y 1989 - mostrara esa rivalidad de Estados y a la vez de sistemas. Después de 1945 ello se encarnaría con intensidad cambiante a través de las décadas, principalmente en dos grandes Estados; a la vez sería en constancia notable un centro de la polémica al interior de los cuerpos políticos, de los países, en suma, en la gran mayoría de las naciones del mundo. También, la crisis ideológica mundial del siglo XX no abolía la tendencia de relacionamiento internacional arraigada en costumbres y percepciones a veces muy antiguas, así como tampoco sus tradiciones y tendencias de política exterior. Las modificaba eso sí. Es un marco general que se debe tener en cuenta al momento de comprender la posición internacional de la izquierda chilena.

\section{ACTOR DE UNA ESCENA MUNDIAL}

Desde su nacimiento, al menos como izquierda antisistema, existía en su seno el convencimiento de que sus ideales e intereses eran internacionales y parte de una 
transformación mundial. En Chile, como en tantas partes a lo largo del globo, las metas consistían no solo en un objetivo justo, sino que en un combate por llevar a cabo una transformación de la sociedad, donde la voluntad era al mismo tiempo el alma de un proceso inevitable de cambio. La URSS y otros actores, todavía no a cargo de un Estado, eran pruebas vivientes de que la fuente de resistencia eran solo los intereses sectoriales, de clase dominante o la carencia de ilustración, en todo caso destinada a ser dejada atrás, eliminada naturalmente. Tras la Segunda Guerra Mundial, el surgimiento impuesto por la URSS de los regímenes marxistas en Europa Oriental, en Yugoeslavia por un triunfo armado endógeno de los comunistas de Tito, y luego en 1949 con el triunfo comunista en la guerra civil china, junto a Corea del Norte, proporcionó una prueba práctica, vital, de enorme fuerza emocional/ racional, acerca de la inevitabilidad histórica. Que un tercio de la humanidad hubiera emprendido el camino hacia el socialismo parecía, hasta la década de 1960 en nuestro país, una especie de prueba irrefutable de la necesidad histórica. Siempre el triunfo es el mayor aliciente para el triunfo, por el poder hipnótico que el éxito práctico ejerce sobre la mente y hasta el alma de la gente.

Es lo que alentaba a la Unidad Popular desde sus raíces últimas, puesto que en cierta medida correspondía a la expresión formal de una religión política en la era de la secularización establecida (¿postsecularización?): se sentía parte de un movimiento global y no meramente de una transformación espontánea. De esta manera, la izquierda chilena, al menos esta que aquí se califica como tendencia o francamente antisistema, estaba poseída por una visión de mundo, de ser y deber ser, que era a la vez nacional e internacional. Esto último se refiere a lo que aquí ya se ha dicho: los sucesos globales le proporcionaban ínfulas para pervivir y prosperar políticamente en el medio chileno.

¿Y lo nacional?

Se alude no solamente al hecho de que los humanos no se articulan en una agrupación universal, salvo entidades parciales y/o temporales (China, Roma), sino que lo más permanente en la historia han sido las sociedades; en la modernidad, los Estados nacionales. Este es un primer punto. El segundo, que ello se insertaba en la experiencia chilena. No solo como una parte con alguna tipicidad propia del mundo hispanoamericano, que además lo es; sino que, mirada en sí misma, hasta cierto grado representó en la región un tipo de "excepcionalidad". Ello porque en una mirada comparativa había más institucionalización política, lo que conllevó que las instituciones políticas del Estado tuvieran más consistencia relativa. Esto último, porque estamos muy conscientes de las crisis que, de tanto en tanto, se abaten sobre el país. En todo caso, en Chile la institucionalización precedió a la movilización. La ampliación política en torno al 1900 les confirió una oportunidad creciente a las posiciones antisistema de participación rupturista, pero con límites. 
Desde entonces, se desarrolló el proceso democrático a partir de una situación relativamente oligárquica —aunque pluralista y, se repite, institucional— entre el XIX y el cambio de cultura y de actores en el curso de la tercera década del XX. Pero se le añadió otro factor.

\section{HACIA UN CAMBIO REVOLUCIONARIO EN DEMOCRACIA CUASI- CONSOLIDADA}

Mientras en Europa y en nuestra América la década del treinta es asociada a la crisis de la democracia, en Chile desde 1932 comienza un período donde la democracia política —en gran medida, la democracia en sí misma- alcanza su máxima expresión y, muy importante, comienza a llamar la atención continental y más allá de ella. Fue el momento donde el ser o no democrático crece como un tema de las relaciones internacionales y, más ampliamente, de la política mundial. También fue el momento donde apareció en forma un fenómeno nacional e internacional del Chile político, un paralelismo asombroso entre las formas - y quizás no poco en el contenido- de la evolución política europea y chilena. Parte de ello fue la instalación entre 1931 y 1932 de una izquierda marxista en el sistema político e institucional del país. Lo de "marxista" no sería estático, pero existe casi sin discontinuidad una permanencia en la evolución hasta 1973. Un Partido Comunista, típica hechura de la Tercera Internacional, actuando en esa larga marcha a través de las instituciones, hasta constituir una subcultura política con rasgos propios al interior de la sociedad chilena. Inseparable del modelo soviético — en algunos sentidos le antecedía—, sus raíces chilenas demostraban tanto autodeterminación como, al igual que el país, una sociedad universalizada. Llegó a ser — junto con el cubano, que no fue el actor que llevó a cabo la revolución-el partido comunista más relevante de América Latina.

A su lado, en los cuarenta, emergían y rivalizaban diversos grupos del socialismo chileno; a veces unificado, otras, disperso, entre nacionalistas de izquierda, populistas y reformistas (lo que después sería evaluado como oprobio). Entusiasta por un cambio drástico imposible de realizar si se tenía una meta de democracia política, el socialismo fue derivando y convergiendo en una meta revolucionaria. Su reunificación en 1955 y su estrategia del "frente de trabajadores", es decir, de alianza solo con fuerzas — en nuestro lenguaje - antisistema, determinó una alianza llena de rivalidades, pero al final relativamente sólida con los comunistas. Esta convergencia traducía la creciente radicalización política de los socialistas, en proceso ininterrumpido hasta 1973. Una de las diferencias, a veces enojosas, entre socialistas y comunistas, había radicado en la posición hacia la URSS, que era para los comunistas como la fuente de vida en términos de valores políticos, amén de 
ayuda económica y logística. En cambio, para la mayoría de los socialistas, si bien reconociendo muchos aspectos "positivos" en lo económico y social del régimen comunista, rechazaban en parte su sistema político y la adhesión incondicional a su política exterior. Esto fue particularmente agudo al comienzo de la Segunda Guerra Mundial, debido especialmente al pacto nazi-soviético. Incluso, algunas facciones socialistas apoyaron la Ley de Defensa de la Democracia -prohibición del Partido Comunista- en 1948, y otras, entre ellas la del futuro canciller de la Unidad Popular, Clodomiro Almeyda, admiraban a Perón. No fue el caso de Allende, quien al igual que los comunistas, veían en él un "fascista".

Con todo, en un desarrollo que aquí sería largo explicar, se fue produciendo el acercamiento entre el socialismo y el comunismo, lo que cubría prácticamente casi toda la izquierda política. En lo internacional, que es lo que aquí más interesa, sin perder ni un momento de vista que lo interno y lo externo conviven estrechamente, el panorama global ayudó a la convergencia de la izquierda. Los socialistas comenzaron a restringir cada vez más cualquier expresión de distancia ante la URSS, mientras los comunistas mantuvieron incólume su paradigma expreso frente a ella, incluso de manera marcada ante las intervenciones de Moscú en Hungría (1956) y Checoslovaquia (1968). Ambos, no tuvieron ninguna distancia ante el proceso de descolonización, pudiendo sostener como paradigmas a varios de ellos. Los socialistas, mientras unificaban sus varias facciones — separadas por visiones ideológicas instrumentales, también por camarillas y cacicazgos-, por un momento admiraron a la Yugoslavia de Tito, nada de democrática, pero no impuesta por Moscú. Después se entusiasmaron con otra revolución total, dictadura despiadada, no marxista, la argelina. Finalmente, convergieron en la revolución cubana y en el régimen de Castro, un modelo más obligatorio y cercano. Los comunistas estaban menos entusiasmados por este último como estrategia de acceso al poder, pero sí seguían fieles a la idea de la alianza entre Castro y Moscú.

A la vez, ambos partidos llegaron a compartir, ya antes de 1970, una admiración y relación directa con el régimen de Alemania Oriental, la República Democrática Alemana (comunista). Este es un caso que llama la atención. Fue un atractivo desde ambas partes. Para el régimen comunista era interesante el único lugar del mundo donde había dos partidos marxistas ("marxista-leninistas", les aseguraba Carlos Altamirano; Salvador Allende defendía el Muro) aparte de Berlín Este (de allí el Partido Socialista Unificado, el SED), Chile, ya que ese régimen se había erigido sobre la fábula que había resultado de la fusión de los dos izquierdas, la comunista y la socialista. Así, en Chile los alemanes veían conformarse su propia trayectoria. Y los chilenos, la confirmación de que podría sobrevivir el pluralismo en una república socialista, con varias izquierdas; una ficción que a ese régimen le era necesaria, lo mismo que a la izquierda chilena. 
Me detengo en este hecho porque resalta un rasgo del período de la Guerra Fría que, a veces, se descuida u olvida incluso en la mejor literatura al respecto. Lo que destaco es que la Guerra Fría no fue solamente una confrontación entre dos superpotencias - denominación común- que alinearan al resto del mundo; la multipolaridad le era tan propia en una diversidad de centros o Estados — de allí lo de "policentrismo" - como, por cierto, la bipolaridad de los dos grandes. Y existe otro factor, tanto o más fundamental que los anteriores. Cuando se habla de "crisis ideológica" se refiere que el gran conflicto ocurría a nivel de sistema internacional, interestatal. Pero también tenía lugar, en un momento u otro, en la gran mayoría de las sociedades de la tierra relacionadas con la modernización o meramente tocadas por ella.

Esto último fue muy marcado en el caso chileno, cuyo arco político desde el XIX seguía los lineamientos europeos. Por ello, era altamente probable que experimentara la crisis ideológica del siglo XX en su propia carne, como en efecto así ocurrió: el modelo occidental, la democracia liberal, o el modelo revolucionario, y entremedio una amplia panoplia de posibilidades. Por ello, aquí reside un cimiento fundamental de la Guerra Fría, que, en sus raíces ideológicas, en sus conflictivas visiones acerca de lo que debía ser el país y el mundo - y que incluía algo propio de la disyuntiva, la búsqueda de un "tercer camino"-, había echado raíces en el cuerpo político chileno con mucha antelación, ya a fines del XIX. Este factor tenía paralelos en una gran cantidad de países a lo largo del globo. Explica el efecto instantáneo de la revolución rusa en el país, así como el de la guerra civil española. Lo que se le añade a partir de 1945 fue que esa disyuntiva política fue personificada por las dos grandes potencias y, con ello, personificó al sistema internacional. En ese marco, los intereses de Estado se fundían, o empequeñecían según el caso, con los propósitos y furores político-ideológicos. En fin, este fue uno de los dilemas de la política moderna que estuvo presente - en diversos momentos - a lo largo de la inmensa mayoría de las sociedades humanas, en grados distintos, pero siempre haciéndose notar.

\section{DOGMA “ANTIIMPERIALISTA” Y DEMOCRACIA}

América Latina — surgida de dos fenómenos globales, la expansión europea del 1500 y el nacimiento de la política moderna del 1800 - fue un campo favorecido de este enfrentamiento. Todavía resta algo de esto en la vida política, más que en otras zonas del mundo. Y Chile, desde el XIX, sostuvo un desarrollo político más identificado en las formas con la evolución europea. A mediados del XX emergía con claro perfil, más que en cualquier otro país latinoamericano. Una izquierda 
marxista sólidamente instalada en el sistema político (así como también una constante antimarxista, que por momentos podía intensificarse, aunque de duración acotada) empezó a llamar la atención como un polo político o un peligro, según la perspectiva. Que ocurriera al mismo tiempo en que, desde la Segunda Guerra Mundial, comenzara a llamar la atención este país del sur como una de las pocas democracias existentes en la región, lo hacía más peculiar todavía. Ambas realidades se superponían, o quizás a veces se contradecían.

Desde esta mirada internacional, que incluye la vida interna de los países, se podía converger con facilidad en el antïmperialismo. Esto podía alcanzar un estatus representativo de un sentimiento nacional mayoritario. Incluso podía identificar a sus rivales. No fue patrimonio de la izquierda marxista, pero esta fue su portavoz más sincero y sistemático. Es un sentimiento que cubría amplias gamas de la conciencia regional, e incluso tiene comparaciones en reacciones globales ante el fenómeno norteamericano del XX y su rasgo de potencia hegemónica. Solo que en América Latina - y en otras latitudes - tiene una contracara, el otro lado de la medalla: la admiración o identificación con algunos fines o con la mayoría de los elementos del EE.UU. cultural, económico y político. Y no se crea que esto se trata de dos grupos o sectores sociales con intereses encontrados. Ambos sentimientos, pro y antinorteamericano, pueden habitar como dos almas en un mismo cuerpo de las mismas personas. En Chile, a lo largo del siglo XX, todos los actores políticos fueron pro y antinorteamericanos, no al mismo tiempo, por cierto. $\mathrm{O}$, lo que es casi lo mismo, en un momento u otro demandaron una intervención de EE.UU.. Esto es casi la historia misma de América Latina.

Al posicionamiento radical contra EE.UU., que conjugaba transformación interna con externa como orientación hacia el socialismo, aquel de los "países socialistas", se le añadió la identificación con el "tercermundismo", diferente al "no alineamiento" en su sentido original. Ya no se trataba de equidistancia entre las superpotencias, sino de convergencia con las revoluciones marxistas exitosas, en especial los tres modelos antes mencionados. Salvo algunas cualidades particulares de ciertas revoluciones tercermundistas antioccidentales, los testimonios de la época hasta 1973 solo se refieren a aquellas o a actores políticos que se movían en esa dirección. Solo esos modelos constituían democracias económicas y sociales, la verdadera democracia.

Y existía el otro rasgo que ayudó a configurar la imagen internacional de la "experiencia chilena": se dio en el medio institucional de una democracia liberal relativamente madura, si bien no llevaba el paso de su complemento económico y social, la simiente de tantas crisis en el tránsito del antiguo régimen a la modernidad. La idea de un "tránsito al socialismo" desde una base institucional, y con las bases y parte del aparato henchidos de nostalgia por una "revolución de verdad", se 
cambiaba por una meta revolucionaria, pero mediante la "vía chilena", es decir, institucional. Allende se lo dijo con todas sus letras a los dirigentes comunistas en Berlín Este en 1967: él era "el Fidel Castro de Chile", con la sola diferencia de que lo haría por métodos pacíficos.

Porque al estar esta izquierda tan instalada en el sistema político chileno (y en su mundo educativo, cultural y sindical), como parte de las instituciones intentando siempre empujarlas a ser parte del "socialismo" en el sentido antedicho, también adquirió algunos de los aprestos del mismo sistema, aunque nunca compartiendo la legitimidad. Esta era comprendida solo como un "tránsito", como un momento de transformación de "la correlación de fuerzas" que mueve al mundo "desde el capitalismo al socialismo". Lo que habría de democracia en el sistema institucional, rezaba la tesis, se debía solo a la existencia de la misma izquierda, y ella sola produciría la verdadera democracia en ese orden socialista. De hecho, el mismo principio antiimperialista combinaba la transformación interna con la externa en la búsqueda de lo que se suponía una verdadera democracia.

El concepto de "constitucionalismo" empleado profusamente por mucha literatura y, sobre todo, por los dirigentes y altos funcionarios de gobierno en los años de la Unidad Popular, solo pasó a tener presencia en el lenguaje de la izquierda chilena a partir de la noche del 4 de septiembre de 1970, como un activo que consolidaba la legitimidad -amén de legalidad- del gobierno de Allende. Algo parecido sucedía con la "seguridad nacional", concepto preferido del mundo militar desde antes de la revolución cubana, pero que Allende también utilizaba a menudo, con insistencia en su sentido más positivo. Era parte del juego entre el Gobierno y la oposición por ganarse el sentimiento de los uniformados. Traería más de una paradoja en los años que seguirían.

\section{ESTRATEGIA INTERNACIONAL, CORRELACIÓN DE LO INTERNO Y LO EXTERNO}

De esta manera, la transformación al interior del país era vista como un mismo fenómeno en lo interno y en lo externo. Más importante, era sentida y tenía fuerza moral para la izquierda por el hecho de que en el mundo se perfilaba esta marcha victoriosa hacia el socialismo y porque el sistema tradicional chileno estaba "agotado", sin remedio para meras "reformas". Por otro lado, la Unidad Popular poseía un amplio elenco de altos funcionarios de Estado con experiencia en el manejo de sus ramificaciones internacionales, suficiente como para influir en su dirección, aunque no necesariamente en la sabiduría de la estrategia final. Así como en lo interno el camino institucional le era el más indicado, si se quería tener éxito - a pesar del crecimiento del prestigio de la acción directa en los sesenta, incluso 
organizacional para la guerrilla urbana y de la teorización al respecto- la UP debía plantear algo parecido a una estrategia institucional en lo externo. En este sentido había un entrenamiento de décadas y de éxito relativo. También un crecimiento electoral toda vez que la izquierda, sobre todo en elecciones presidenciales, se empinaba más allá del tercio de los votos; y ya en el Gobierno, una vez alcanzó brevemente a gozar del favor del 51 por ciento, en las elecciones municipales de abril de 1971.

Su estilo, doctrina, impulso de vitalidad política y aprendizaje, los hacía convivir en ese sistema institucional —incluyendo a sectores con tentaciones de acción directa que comenzaban a desbordarse-, pero una vez con las herramientas gubernamentales a su disposición no podían sino avanzar a una meta que no podía ser otra que aquella del socialismo, a grandes rasgos prefigurada en los modelos favoritos. Había un impulso moral imposible de no obedecer. El sueño de la izquierda antisistema era la meta revolucionaria; lo que sabía hacer consistía en la adaptación y el avance institucional. No podía abandonar lo primero, por lo que debía efectuar el salto dentro del marco del sistema, que le daba oportunidades y obstáculos para alcanzar la meta. El impulso inicial que le otorgaba la dinámica al proyecto provenía de la política mundial. Chile era, y es, en importante medida una de sus muchas creaciones, como tanta sociedad a lo largo del globo. La política exterior era una de sus caras.

Existen dos premisas previas para entender su despliegue. Uno es lo ya señalado, que el mundo entero se encuentra en ese "cambio de correlación de fuerzas entre el socialismo y el capitalismo", en detrimento de este último, que sería lo que ordenaba ese drástico golpe de timón en la historia de Chile. No era nuevo, ya que la tesis, cual apocalipsis predicado, que provenía de raíces teológicas y teleológicas, se encontraba en Chile en la base de la izquierda antisistema desde el 1900. Como buen marxismo, a la esperanza quiliástica en síntesis explosiva se le añadía el lenguaje científico, alianza de apariencia imbatible. El cambio nacional no era más que un eslabón del cambio global. Además, en América Latina abriría un campo ya preparado por la revolución cubana.

Que la "experiencia chilena" era una con una evolución más o menos estremecedora a nivel mundial, proviene tanto de ese fervor metahistórico por el salto hacia una sociedad final, el "fin de la prehistoria" e inicio de la verdadera historia. No es otra cosa que un viejo mito - anclaje humano para seres devorados por el tiempo- del "fin de la historia", y esa historia que seguiría a la prehistoria tiene un sospechoso parecido con el redivivo "paraíso sobre la tierra". Y proviene también del materialismo hecho carne, en indisoluble fusión, como una religión política, unidas por la fe absoluta en la existencia una plusvalía que, según se suponía, era científicamente constatada como ganancia ilegítima —aunque imposible de 
evitar incluso por el mismo capitalista - y que estaba detrás de todas las privaciones de los desposeídos. A nivel internacional eso se replicaba con el capitalismo global, cuyo corazón era EE.UU., la potencia además encargada de apoyar por la política y las armas la estructura del capitalismo que ya comenzaba a erosionarse. La esencia, el ser del ente si se quiere, eran entonces los "excedentes", palabra que todavía en nuestros días cumple una función totémica concitando energías protestatarias. Es una de las razones por las que el "antiimperialismo" era el cemento ideológico que vinculaba a esta religión política. Ejercía, como se ha dicho, cierto magnetismo más allá de la izquierda agrupada en la Unidad Popular, y puede alcanzar por momentos a identificar a la mayoría del cuerpo político, aunque por períodos cortos. Es el alma más visible de la autoconciencia internacional de la región. Que no se olvide por un instante que es una de las dos almas; la otra, empática con la experiencia norteamericana en casi todos sus sentidos, está más mimetizada y por lo mismo puede ser más poderosa en el largo plazo. La revolución institucional o vía chilena iba a ser posible sobre los hombros de esos "excedentes" que, cual talismanes, encendían la imaginación.

La revolución por vía institucional en lo interno demandaba como contrapartida un cambio también incremental, incluso bastante menos pronunciado, en todo lo que se refería al sistema internacional. En principio rompía con el imperialismo y la hegemonía, vinculándose a países y pueblos liberados o en vía de liberación. Era una apuesta rupturista en el sistema internacional. Por otro lado, el ser interpretado como un proyecto no ortodoxo de cambio hacia un socialismo, debido a su origen institucional (elecciones, parlamento independiente, etcétera), representó un activo muy fuerte que a la postre arrojaría una sombra o una luz -como se quiera- sobre el Chile que seguiría tras 1973, hasta el día de hoy. Ello demandaba una política flexible entre rupturismo y acomodación.

Esto era algo diferente a un acomodamiento a la realidad internacional de las revoluciones radicales. Estas combinaron un desafío radical al entorno cercano y lejano, siendo la única excepción en su purismo la de los talibanes en Afganistán desde 1995 a 2001. En ese avenirse a la realidad internacional existe tanto un imperativo de supervivencia como un aceptar la realidad, entendida como intereses históricos de Estado dentro de un sistema de Estados, con una lógica que no se puede descifrar dentro del código de la persuasión política (ideología, o fines ideales). Sus modelos caben perfectamente dentro del desarrollo del gran paradigma del siglo XX, la revolución rusa entre Brest-Litovsk (3 de marzo de 1918) y el Pacto Nazi-Soviético (23 de agosto de 1939), este quizás uno de los más extraordinarios volte-face de la historia internacional. Más modernamente, podría calificarse aquí las relaciones entre el régimen de Castro en Cuba con la España de Franco, un tipo de relacionamiento hasta cierto punto emulado por la relación Franco-Allende. El 
gobierno de la Unidad Popular aprendería mucho en este sentido, aunque el golpe de 1973 haya arrojado una sombra sobre su recuerdo. Existía más de un elemento en la naturaleza internacional de la sociedad humana que no estaba en las expectativas de las persuasiones ideológicas.

\section{POLÍTICA EXTERIOR: PERSPECTIVA IDEOLÓGICA Y REALIDAD INTERNACIONAL}

Por ello, la política exterior de la Unidad Popular debía tomar en cuenta esta complejidad, que además tenía elementos a su favor, en especial por la ola de simpatía americana, europea-occidental y tercermundista, no siempre proveniente de una perspectiva marxista, que acogió y que su diplomacia y su presentación política externa supo aprovechar. Su estrategia fue definida por sus responsables como la de ayudar y posibilitar el proceso de tránsito al socialismo de la sociedad chilena. Aunque de esta forma solo se verbalizó después del golpe, me parece que es útil para entender lo central de su política exterior, manejada en lo principal por el canciller Clodomiro Almeyda.

Por lo tanto, preveía instancias como la de Brest-Litovsk, ajustes tácticos para apoyar la estrategia; así como un firme propósito de interpretar o re-interpretar los intereses internacionales de Chile desde su interpretación esencialmente política (ideológica si se quiere). No necesariamente significa abandono de la doctrina internacional —aunque en el largo plazo en los sistemas revolucionarios sí lo ha sido- - pues quien en nombre de un cambio radical premunido de una ética de la convicción adquiere el poder del Estado, tiene la necesidad de ajustarse en algunos grados a la ética de la responsabilidad para sostener ese mismo poder. En general, la política exterior del gobierno de Allende ha sido considerada como exitosa. Diría que en términos tácticos lo fue, no así en términos estratégicos (solo si uno no comparte la tan vital visión de mundo y sentido de mandato que la inspiraba).

\section{DESARMANDO LA HOSTILIDAD REGIONAL}

Un primer campo de prueba del acomodamiento es el de las relaciones latinoamericanas, exceptuando por cierto el caso cubano. Esto era delicado, por la proliferación de regímenes militares en la región y el aislamiento de Cuba frente a ella. Este último, sin embargo, comenzaba a llegar a los límites, y crecería una tolerancia al régimen de Castro. La izquierda chilena era vista como una amenaza potencial por los regímenes de Argentina y Brasil. Sin embargo, la diplomacia de la Cancillería y la del mismo Allende supo desplegar una política de coexistencia no agresiva, incluso 
convergente en algunos aspectos. El régimen argentino comenzaba a naufragar, y Buenos Aires vio una oportunidad de adquirir credenciales progresistas en una buena relación con Allende, a pesar de un fondo de desconfianza. Incluso culminó una antigua negociación para acudir a un tribunal internacional por el diferendo del Beagle. Existía una desconfianza de fondo, en todo caso encogida por estos factores. Más todavía, en paradojal analogía a las relaciones con el gobierno de Franco, se puede decir que serían más fecundas que con el reemergente peronismo. En realidad, la convivencia con este último fue de solo pocos meses y Allende vio claramente que la autoafirmación del viejo caudillo por sobre Cámpora no era buena para su proyección internacional, ello a pesar de que desde los años sesenta el Ejército argentino - entonces un actor político en todas las condiciones- había designado expresamente (sin publicidad) a la izquierda chilena como uno de sus enemigos.

Con el Brasil del régimen militar no hubo tregua, aunque tampoco hubo hostilidad pública. La cancillería chilena intentó evitar todo roce, a pesar de que Brasilia ejercía un antimarxismo evidente como política latinoamericana, y se miraba a sí mismo como la contrapartida del régimen de Castro, que además apoyaba una guerrilla urbana en Brasil. Con Chile fue una pugna silenciosa en el tablero. Si bien Brasil alentó a los militares y a políticos chilenos a derrocar a Allende, ello solo tuvo efecto en los meses inmediatamente anteriores al golpe en Santiago. Sería mucho decir que la política de la Unidad Popular aisló a Brasil, gran actor regional entonces, pero sí logró hacer inmune a La Moneda ante un cerco más decidido que, al menos en 1971 y 1972, pudo haber efectuado el régimen brasileño.

Ciertamente, en 1970 cundió una ola de alarma con la elección de Allende como presidente. Estuvo más bien restringido a los gobiernos y a unos pocos círculos políticos, que fueron poco a poco siendo neutralizados por la ola de simpatía relativa hacia la "experiencia chilena", que rebasaba más allá de la izquierda latinoamericana. Esto operó para que los gobiernos de la región fueran morigerando su posición de desconfianza, dando paso a una actitud más cooperativa hacia La Moneda, incluso haciendo ademanes de amistad. Caso aparte fue el de México, ya que una ostentosa demostración de solidaridad con muchos aspectos del proyecto de la Unidad Popular era parte de la auto interpretación del régimen del PRI (Partido Revolucionario Institucional). Nada de ello obstaba para que la capital azteca intercambiara ideas con la Casa Blanca, convergentes con las de esta última en lo relacionado con Chile, otro rasgo repetido de la era del PRI. Con Bolivia, pese a no existir relaciones diplomáticas a nivel de embajadores, existía un nutrido intercambio y hubo algún deshielo durante el régimen militar de izquierda nacionalista de Juan José Torres. Cuando fue sucedido por un antimarxista, igualmente militar, Hugo Banzer, este 
mostró distancia ideológica, aunque siempre en las relaciones con Chile todo estaba supeditado a la aspiración de "salida al mar".

Una paradoja especial fue el caso de Perú. El régimen militar instalado bajo la égida de Juan Velasco Alvarado en octubre de 1968, fue recibido inicialmente con el repudio reflejo de la izquierda chilena. Luego, en especial los socialistas, lo mirarían con especial favor, insinuando en casos dramáticos su potencialidad de ser imitado en Chile. Sin duda, Allende le tenía simpatía —aunque condenó inicialmente el golpe - e hizo todo lo posible para mostrarlo como una contraparte política. Todo ello estaba también permeado por la sombra de 1879. Muy luego, la diplomacia de la Unidad Popular — no así sus fuerzas políticas - captó el peligro de un régimen dominado por un propósito revanchista, es decir, de cobrarle cuentas a Chile incluso con un conflicto armado. Esto lo tiene que haber tenido muy claro Allende, que había enviado como embajador a un dirigente socialista cercano a él, que le enviaba informes en este sentido. Esto no quiere decir que el gobierno de Velasco no estuviera tensionado también por sentimientos contradictorios, a favor y en contra de Allende. Al adquirir grandes partidas de armamento soviético que Chile no podía equilibrar, la tentación de obtener una "reparación histórica" aparecía demasiado atractiva. Por mucho ademán "antiimperialista" de Velasco, siempre al final alcanzó un acuerdo práctico con Washington, lo que estaba fuera de las posibilidades y la voluntad de Allende.

\section{EUROPA OCCIDENTAL, LA BENEVOLENCIA}

Algunos gobiernos europeos miraron con desagrado el triunfo de Allende, aunque, por cierto, la región latinoamericana nunca ha estado en el centro de sus atenciones, al menos en el siglo XX. La Europa política, la de las democracias y no la de los sistemas marxistas, desde luego — se verá el caso de España-, no eran solo los gobiernos, sino también una opinión pública y una intelligentsia a la que le interesó la región latinoamericana, en especial a raíz de la revolución cubana, pero también por una antigua búsqueda del bon samvage. Europa emergía de su propia revolución cultural de los sesenta, simbolizada por París 1968, y la izquierda democrática ansiaba hallar otra Primavera de Praga que conciliara democracia con socialismo, y creyó hallarla en el Chile de Allende.

Este remoto país, poco exótico para los paladares europeos, antes casi desconocido, se transformó en una celebridad y llegó a ser una especie de utopía que les sonaba familiar. Esta visión era contagiosa; los periodistas e intelectuales que visitaban el país del sur veían en lo fundamental una democracia política y un país alegre, aunque casi no conversaban con los opositores; los seducía la hospitalidad de 
los anfitriones, porque al revés de las revoluciones triunfantes, parecía espontánea. Por unos pocos pesos llevaban una vida placentera en un país que sentían como nuevo. Se contagió con algo de esta benevolencia al mundo liberal europeo, y no dejó inmune a los conservadores. La empatía con la "experiencia chilena" — habría que profundizar en este concepto- no nació de la diplomacia chilena o de un proyecto de la Unidad Popular, sino que fue parte de la historia íntima de la cultura europea en los años de la Guerra Fría. Por cierto, la acción de La Moneda en esto, diplomáticos profesionales y gente de confianza de la Unidad Popular, como la doctrina del mismo Almeyda, olvidando su maximalismo, supo adecuarse plenamente a esta recepción. Los gobiernos y parte de los cuerpos diplomáticos no se engañaban; pero algunos funcionarios y los parlamentos, como la gran prensa, ponían el acento en la "comprensión", amén de que los viajeros quedaban encantados con Allende, que dedicaba mucho tiempo a los visitantes.

La descripción anterior casi está calcada de la mirada de la Francia de Pompidou. De hecho, Le Monde, entonces en la cima de su influencia, se convirtió en prácticamente un vocero de la Unidad Popular en Francia y Europa como expresión de un "frente popular" redivivo. Esto jugó un papel en las elecciones parlamentarias de marzo de 1973, simultáneas con las chilenas. Francia fue la sede del Club de París, los acreedores "capitalistas" de Chile, y a pesar de las vehementes protestas de los norteamericanos — que no llegaron tan lejos— le otorgó un respiro a Chile. Los jueces franceses simpatizaban con la causa chilena ante demandas de una empresa de cobre norteamericana expropiada; eso sí, encontraban un poco mucho que la parte privada no pudiese reclamar a otra instancia que no fueran tribunales chilenos que fallaban constitucionalmente contra ella. En total, funcionó mucho lo del buen salvaje, aunque el mismo Pompidou era muy escéptico del carácter benévolo del proyecto chileno.

Alemania Federal fue un caso especial. Se trata de un país que ha jugado —incluyendo la inmigración del XIX — un papel protagónico en las relaciones internacionales de Chile, con excelente imagen. Chile estaba matriculado con el reconocimiento del gobierno de Bonn. La izquierda, comenzando por el propio Salvador Allende, había llegado a tener como modelo al régimen de Berlín Este. Pero Allende se daba cuenta de la importancia de Bonn y simpatizaba — como los comunistas - con la Ostpolitik de la coalición liderada por socialistas y liberales, con Willy Brandt como canciller. El reconocimiento de Alemania Oriental por La Moneda era pésima notica para Bonn, que tenía que lidiar con la expropiación de intereses alemanes en Chile. Sin embargo, también se dio una división dentro del mismo gobierno alemán. Incluso la Democracia Cristiana (CDU), entre otras cosas, uno de los sostenes económicos de su contraparte chilena, no fue inmune a la seducción por parte de la imagen de la Unidad Popular. 
Algo no muy distinto sucedió en el Reino Unido, a pesar del escepticismo del gobierno de los conservadores de Edward Heath. El lobby en favor de Chile sería un factor permanente de la mirada inglesa hacia el país del sur, no sin ambigüedad. La Italia de la partitocracia por cierto se matriculó en esta línea de identificar a la Unidad Popular como una coalición de izquierda intrasistema (en relación a la democracia), y a la DC italiana le parecía extraña la política liderada por Eduardo Frei, de oponerse frontalmente al proyecto de la UP. Más radical, en este sentido, fue la política de la Suecia de los años de la hegemonía socialdemócrata, liderada por Olof Palme. Este apoyaba sin remilgos al régimen de Castro y a Vietnam del Norte, como sistemas legítimos y merecedores de ayuda; era parte de una identificación antinorteamericana que caracterizó a este país por largos años, la mayoría de la época de la Guerra Fría, sin efectuar crítica alguna al dominio totalitario en Europa.

Un caso especial de esta Europa fue el de España. Desde la guerra civil de los treinta ambas historias han estado imbricadas, directa o indirectamente. La izquierda chilena que llegó al gobierno con Allende había bebido una parte de su cultura política de la experiencia española y de las "lecciones" que creyó sacar. En menor medida, lo fue para el resto de las fuerzas políticas chilenas (la historia continúa). 1973 sucedió (en alguna medida, por cierto) como repetición entrenada de 1936. Para la izquierda chilena Franco era una de las figuras que concitaba odio y burla. Pues bien, las relaciones fueron mucho mejores de lo que era de predecir, y no por puras razones diplomáticas, en un sentido estrecho de este último concepto. Allende intentó y tuvo éxito en tener una relación flexible y convergente con el gobierno español, no dejando de emitir alguna alabanza al caudillo; lo mismo el embajador de Chile ante Madrid, un amigo del presidente. Era una época en que desde distintas trincheras se alababa el desarrollo económico y social de España, a veces aplicándole el calificativo relativamente correcto de "dictadura de desarrollo". Lo mismo para una parte del aparato franquista, que no había vivido los odios desatados de los 1930 y se estaba preparando abierta o soterradamente para la España post Franco. Creo que operó otro factor, sobre todo desde Madrid, un nacionalismo que nunca dejó de mirar a 1898. Fue una de las razones de las buenas relaciones entre los regímenes de Castro y Franco; quizás el primero aconsejó a Allende en este sentido. Franco, junto con una estrecha alianza con EE.UU., no dejaba de marcar una diferencia con EE.UU. por el caso cubano.

\section{EE.UU. ¿FUE LA GRAN BARRERA?}

La imagen del "imperialismo yanqui" (o yankee), como se decía, ha expresado una esfera del alma de los latinoamericanos. Ha estado imbricada con la izquierda chilena 
desde fines del XIX. Las izquierdas convergieron en ella de manera casi unánime al añadírsele el paradigma de los sistemas marxistas, cada grupo poniendo el énfasis en el paradigma que más lo identificaba. Y ha sido invocada en todo tipo de revolución tercermundista, casi nunca democrática, aunque emplearan profusamente el término. La personificación del mal, EE.UU., se traducía en la "alianza objetiva" entre la oligarquía nacional y los intereses capitalistas del imperialismo. La simple propiedad de la gran minería del cobre abriría las puertas del desarrollo y financiaría la "vía chilena". Lo mismo se decía de manera expresa en el programa, que no se era partidario de la inversión extranjera salvo casos muy calificados. Se trataba de un "enemigo necesario" para fundamentar la propia persuasión.

EE.UU., que había detectado tempranamente el caso particular de Chile, había apoyado a las fuerzas antimarxistas en Chile desde comienzos de los sesenta (al menos desde ahí está documentado), consciente de que también Moscú apoyaba a los suyos. Réplica de una pugna más o menos global. En paradoja nada de extraña, todos los sectores políticos en un momento u otro habían solicitado algún tipo de intervención norteamericana. Con todo, no quedaba duda que, por convicción y doctrina, la izquierda era antinorteamericana y de poco servía asegurar que no estaban contra el "pueblo norteamericano". Más que por su posición geopolítica, lo que importaba para Washington en el caso de Chile era su impacto regional, además porque en los cincuenta y sesenta había sido señalada como una de las pocas democracias que funcionaban como tal en la región. La intimidad de esta izquierda con Moscú, la Habana y Berlín Este era un tema de preocupación para Washington; y viceversa, la izquierda estaba convencida de que solo distanciándose de EE.UU. podía construirse un verdadero socialismo.

Durante toda la Guerra Fría fue política de Washington tratar de impedir o a veces intervenir activamente contra un triunfo de una revolución marxista. Pudo convivir perfectamente con la gran mayoría de las dictaduras nacionalistas, antioccidentales, pero era casi imposible hacerlo con una marxista, excepción hecha de Yugoslavia, único caso de real "no-alineamiento". A veces se tendían algunos puentes con Europa Oriental, o con la Rumania de Ceausescu por ser autónoma de Moscú a pesar de su estalinismo; pero la flexibilidad seguía siendo muy limitada. En los años de la Unidad Popular hubo un cambio notable con el caso de China, en un cambalache que está solo unos palmos más abajo del pacto nazi-soviético de 1939. La visita de Nixon a Peking — como se escribía entonces_ y todo lo que incluyó arrojaba toda una enseñanza a Chile, aunque su verdadera perspectiva solo afloraría mucho después. El eventual cambio de posición de Chile en dirección a un sistema marxista, si era eso lo que se proponía, constituía un desafío a la posición de EE.UU. y de sus aliados, estatales o no estatales. Y, por cierto, por omisión, favorecía a La Habana y también, aunque más indirectamente, a Moscú. 
Por ello, suena a paradoja que Washington haya intervenido más en las elecciones de 1964 que en las de 1970, apoyando con mucha fuerza a Eduardo Frei, pero con menos dirección y selección (y menor intensidad de recursos) en 1970. Esto se revirtió de manera dramática al día siguiente del triunfo electoral de Allende. Y ha sido la fuente de una controversia que no finaliza ni es probable que lo haga en un futuro cercano. Se ha estudiado mucho, y yo he escrito un libro y muchos artículos dedicados a este tema, ellos con muy abundante revisión de las fuentes; y he aportado en porciones de otros dos libros, y dirigido varias tesis universitarias al respecto. Como en otros casos, aquí solo me referiré a presentar un elemental esqueleto del problema.

Es bien conocida la reacción de Washington. Dentro de la complejidad de gestión del gobierno norteamericano, fue un resultado inesperado y le sucedió algo parecido a la derecha en Chile, la estupefacción paralizante. Primero, entre mediados de septiembre y mediados de octubre, fue intentar influir tanto en el apoyo (y empuje) a una intervención militar, como a iniciativas políticas dentro del país para impedir que Allende asumiera el mando, en lo posible cooperando con una salida constitucional, muy parecida a un "golpe blanco". Fracasada ya a fines de septiembre esta última, siguió rondando el apoyo a un golpe militar, que se diluyó a partir de mediados de octubre; pero siguieron cabos sueltos, en conexión con la CIA. Pero esta al parecer no guiaba la estrategia, y se produjo la tragedia del atentado al general Schneider, que por sí misma abortó toda posibilidad de golpe. Esto dejó en el país una marca en la forma de mirar su historia.

Desde la Casa Blanca, donde el tema chileno tendría protagonismo inusitado por casi dos décadas, se dio curso a una política diferente. Siguiendo las recomendaciones del embajador en Santiago, Edward Korry, y los instintos de Henry Kissinger, se decidió por una estrategia de mediano y largo plazo. Consistía en ayudar financieramente a las fuerzas de oposición tanto a sobrevivir la previsible embestida de la Unidad Popular, como en proporcionarle alguna ayuda logística. Todo eso fue además solicitado con diversos lenguajes por los mismos actores de la oposición, tal como la izquierda solicitaba recursos al bloque soviético. Como acciones directas de Washington, se redujo gradualmente la ayuda directa o la que se aportaba a través de diversas agencias. Todo esto estaba dentro de atribuciones legítimas, frente a un gobierno cuyos portavoces desde muy antiguo habían culpado a EE.UU. de casi todos sus males. No tenía por qué ayudar a un gobierno cuyo norte estratégico era erosionar la posición internacional de EE.UU. y sus aliados; no se trataba de un "bloqueo invisible". La política de Washington rompía el cuadro de las reglas formales del derecho internacional, aunque no de la práctica en política exterior: era enviar una señal sostenida de apoyo a las Fuerzas Armadas chilenas al no solo no eliminar la ayuda que desde antiguo les brindaba, sino que aumentarla. 
En lo demás, las políticas públicas de Washington y de Santiago eran casi idénticas. Ambas sostenían que el problema no era entre ambas, sino que de intereses privados. Chile, afirmaba, solo tenía disputas con las empresas del cobre y otros capitales norteamericanos. Washington que se trataba de un asunto legal, que estaba dispuesto a sostener con el gobierno de Chile el tipo de relaciones que este mismo deseara. ¿Cuál de estas estrategias es la que prevaleció? Aparentemente la de Washington; en el relato histórico, la de Allende y la Unidad Popular. Aquí, solo se quiere comprender la dimensión internacional. En este sentido, La Moneda logró romper toda posibilidad de aislamiento internacional. El aliento de Washington a la oposición no significó ningún obstáculo para su presencia y supervivencia internacional. Sus obstáculos internacionales procedían más bien de la comprensión y autocomprensión del mundo como "tránsito al socialismo". Y, aunque esto hubiese sido factible y/o inevitable, ¿hubiese sido en interés ideal de la humanidad y del mismo Chile? Era la pregunta que estremeció a Chile.

\section{LOS PARADIGMAS: MOSCÚ Y EL BLOQUE SOVIÉTICO, CUBA Y CHINA}

Moscú estaba involucrado en América Latina desde la década de 1920, si bien de manera algo lejana, como escenario secundario. Ello no impedía que esperara mantener estrechas relaciones con los partidos comunistas que seguían fielmente su línea. La revolución cubana creó una nueva realidad de compromiso muy directo con la región, y que en un momento hasta amenazó con una guerra nuclear. Con todo, desde el punto de soviético, en lo básico el continente latinoamericano tenía que representar un escenario de relevancia secundaria, dejando a Cuba como un caso especial.

No había unilateralidad. Los actores latinoamericanos buscaban la presencia de Moscú. Los chilenos no lo hacían menos, y al igual que sus congéneres regionales y que otros actores en relación a Washington y a otras capitales, eran bastante pedigüeños. Pero el interés soviético era genuino en el caso chileno. Era el partido comunista más poderoso del continente en relación a la dimensión del país (junto al cubano, hasta la aparición del Movimiento 26 de Julio en su faz radicalizada de los Castro y Guevara) y Chile tenía significación política en la región. De esta manera, pasó a sostener relaciones no solo con los comunistas, desde siempre íntimas, sino que también con el socialismo chileno, a veces sospechoso de "trotskista" desde la óptica de la ortodoxia del Kremlin. Allende recibiría atenciones, ayuda económica (en realidad, "créditos atados", siempre tan criticados cuando provenían de las democracias desarrolladas), más ayuda económica al Partido Comunista y apoyo en las organizaciones internacionales. 
Se percibía que era un país amigo, pero no especialmente privilegiado. Claro, depende de cómo se juzgaba, puesto que los chilenos esperaban mucho más. Educados en la "época del subsidio", de que el desarrollo chileno arribaría de la mano de expropiaciones a la oligarquía, el imperialismo o de la solidaridad de los países socialistas, creían ver el caso cubano y su mantención, en gran medida por la URSS, como anticipo de lo que sucedería en Chile. Esto no se dijo mucho, pero se repetiría en voz baja después del golpe y reluce en los análisis posteriores.

No habían escuchado lo que los mismos soviéticos habían afirmado desde hace tiempo: que la ayuda completa vendría solo a los países "socialistas". Y sucede que en sus propios análisis habían calificado a Chile como "en tránsito al socialismo" -como lo era, por lo demás- y, por lo tanto, en realidad como excusa, no podía recibir la misma ayuda que una Cuba. Tras esto se escondía un hecho que ahora nos parece evidente: que la economía soviética no solo era mucho más débil de lo que aparecía, sino que también era escasa en divisas y allegada al trueque, y Chile no producía casi nada que pudiera interesarle. Sus recursos se ponían en Cuba, en Vietnam, en subsidios en petróleo a países del bloque soviético. No daba para más. Queda la pregunta de cuánto de esto en los años de la distensión no estaba permeado por el propósito de no molestar en exceso a Washington en un tema donde este era sensible, aunque no lo decía mucho. No dispongo de mayores informaciones, tampoco se puede descartar de manera absoluta. De cualquier modo, los chilenos no entendían mucho lo que veían como reticencia soviética ante quien lo único que deseaba era emularlos en su meta. En todo caso, no cabe duda de que el Chile de la Unidad Popular revestía importancia en Moscú como parte de su legitimidad acerca de la futura configuración del mundo; el impacto de la "experiencia chilena" en Europa Occidental le debe haber hecho criar esperanza de que todavía algo similar era posible en Francia o Italia. Era una de las razones por las que Moscú compartía el método institucional chileno, de revolución paulatina "al socialismo".

El bloque soviético todavía tenía mucho menos que ofrecer desde el punto de vista económico, pero para los partidos de izquierda parece que era una fuente probable de provisión de ayuda militar. Polonia, Checoslovaquia y Hungría, a pesar de su historia de revueltas aplastadas por los soviéticos, gozaban de prestigio en la izquierda chilena como naciones socialistas. Pero la que destacó fue la República Democrática Alemana (oriental). No solo porque era el más eficiente estado marxista de la región. Como se dijo, le rebalsaba el prestigio de lo alemán en Chile, de una Alemania socialista. Su mito fundacional de la alianza de la clase obrera era funcional para ambas partes. Berlín Este se interesaba tanto por razones ideológicas (dos partidos marxista-leninistas en Chile, que confirmarían su mito originario) como de Estado, pues recibía en un momento crucial el reconocimiento diplomático de un país que sostenía relaciones con Bonn. Ya desde antes ayudaba a la prensa comunista y socialista y, en general, al aparato militante del partido en 
formación doctrinaria y profesional. Nada menos que a Salvador Allende en 1967, siendo presidente del Senado, mientras solicitaba ayuda económica para el partido y para su "organización ilegal". Es probable que los soviéticos hayan encargado su inteligencia en la región a la eficiente institución de Berlín Este.

El caso de Cuba es bastante extraordinario. Desde 1959 en adelante la historia de ambos países estaría entrelazada por tres décadas. La revolución influyó decisivamente en solidificar la alianza de la izquierda en Chile en torno a un modelo, aunque los comunistas, siguiendo el modelo soviético, tenían sus reticencias. Después, a partir de 1970, ambas partes, Castro y el PC chileno, abrazaron una causa común. Los socialistas estaban fervientemente abrazados a la suya, el guevarismo, aunque en general no llevaran a cabo actividades revolucionarias. Castro apoyó la formación política y militar en Cuba de socialistas y de otro grupo de extrema izquierda, que en 1968 y 1969 iniciaron una guerrilla urbana de muy baja intensidad. El mismo Castro intervino para detenerla y no torpedear así la campaña de Allende en 1970.

De hecho, Castro y Allende mantenían una relación de bastante confianza desde 1959. Aunque Allende nunca propició la táctica castrista en Chile, sí tenía a la revolución cubana en cuanto sistema como un modelo, solo que insistía que su método político de instalarlo en el país del sur sería pacífico. El estilo "verde oliva" impregnó a la izquierda chilena. Chile dio un golpe de relativa audacia al reanudar las relaciones diplomáticas con La Habana apenas unos días después de asumir Allende. No hubo mucha crítica en la región. Lo que Chile podía hacer en Cuba era poco y nada, y no dejó demasiada huella, salvo las espléndidas memorias de Jorge Edwards.

En cambio, La Habana sí que dejó huella en Chile. Ayudó a crear el aparato de seguridad de Allende, aceptado de hecho por todos y con presencia en el palacio presidencial, pero que se encontraba más allá de la legalidad. En principio apoyó (o aceptó algo a regañadientes) la estrategia escalonada de Allende y de los comunistas, y a la vez insistía en la meta revolucionaria. Castro tuvo en su visita a Chile, de más de 4 semanas, un éxito resonante en sus primeros días. La larga y al final tediosa presencia, por convertirse en un actor de la política interna chilena, sin querer ayudó a avivar el fuego de los opositores a Allende. Y dio a entender al final que no veía posible la "vía chilena". Empujaba en 1973 a la izquierda y al mismo Allende a un acto "heroico" y a ganar una batalla militar, pura y simple. Los uniformados chilenos, como sus pares cubanos, en su mayoría habían observado con atención el destino de centenares de oficiales del Ejército cubano, ejecutados en pocas semanas a comienzos de 1959. Por otra parte, la embajada de Cuba, con indudable conocimiento y asentimiento de autoridades chilenas, mantenía un poderoso aparato de seguridad en Santiago, el que sin embargo Allende no quiso activar -según afirmó Castro- la mañana del 11 de septiembre de 1973. Castro había pasado a ser una autoridad moral para la Unidad Popular, pulverizando todo acuerdo a 
medio camino con la oposición interna en Chile, para lo cual por lo demás había muy pocas posibilidades.

China en estos años estaba inmersa en el conflicto (con sangre arribada al río) con la URSS y, por ende, en su acercamiento con EE.UU. Chile, en la transición entre Frei y Allende, había dado los pasos para que en diciembre de 1970 se abrieran relaciones con Peking, entonces una novedad en el continente, con la excepción de la Cuba de Castro. Aparte de unas expresiones de simpatía hacia el gobierno de la Unidad Popular, poco se escuchó venir desde China. Se veía a Chile como un potencial aliado del bloque soviético, y eso era suficiente para marcar distancia. De una interesante carta de Chou En-lai a Allende se desprende una evaluación de la Unidad Popular que no deja de tener sus puntos. Alude a la falta de rigor y de ascetismo entre los revolucionarios chilenos, y critica — sin decirlo- la política básicamente populista en lo económico, de acrecentar el consumo sin exigir sacrificios (era imposible, por lo que se había prometido, además que todavía había un pluralismo político que sacaría en cara la austeridad económica). El dirigente chino pedía asumir el costo de una revolución, para lo cual se había mostrado poco realismo en Chile. La revolución china estaba ad portas de convertir a su clase revolucionaria en establishment, inevitable corolario de su estilo, a la vez que las consideraciones de historia y Estado pasaban a empequeñecer los intereses ideológicos. 


\section{BIBLIOGRAFÍA}

Lo que se expone es una parte infinitesimal de la literatura al respecto. Se la ofrece porque cita una amplia variedad de tipos de estudios y un riguroso examen de la literatura más completa, así como de las fuentes, que los historiadores consideramos fundamental.

Para el origen y evolución de la posición internacional de la izquierda, incluyendo en este primer caso la reacción del Chile oficial y de diversos actores, véase Chile, la Rusia de América. La revolución bolchevique y el mundo obrero socialista-comunista chileno (1917-1927) (2019, Santiago: Centro de Estudios Bicentenario) de Santiago Aránguiz . Para la evolución de esta percepción en la izquierda, véase "El futuro socialista existe y funciona: la Revolución Rusa y la izquierda chilena hasta 1973" (2018, Estudios Públicos, 149), de Joaquín Fermandois.

Para el contexto histórico de la política exterior chilena Mundo y fin de mundo. Chile en la política mundial 1900-2004 (2005, Santiago: Ediciones Universidad Católica de Chile) y Fragmentos acerca del fin del mundo. Artículos y ensayos sobre Chile (2015, Santiago: Bicentenario), de Joaquín Fermandois. Para el derrotero histórico del socialismo, donde incluye su dimensión internacional, está Socialismo y populismo. Chile 1936-1973 (1992, Valparaíso: Instituto de Historia PUCV), de Paul Drake. Para el comunismo, unos episodios reveladores en "The Chilean Communists, Radical Presidents and Chilean Relations with the United States, 1940-1947" (noviembre de 1981, Journal of Latin American Studies, 13[2]), de Andrew Barnard.

Sobre la imagen y magnetismo de la URSS en la izquierda marxista, sobre todo la comunista, "The Rise of the Union between Theory and Praxis: Chilean Communism in the Cold War (1934-1990)", de Joaquín Fermando, en Words of Power, the Power of Words. The Twentieth-Century Communist Discourse in International Perspective (2019, Trieste: Edizione Universitá di Trieste), de Giulia Bassi (ed.). Sobre la percepción anticomunista a lo largo del siglo XX, La creación de la amenaza roja: del surgimiento del anticomunismo en Chile a la "campaña del terror" de 1964 (2016, Santiago: LOM Ediciones), de Marcelo Casals. Aunque no tiene que ver directamente con política exterior, hay que ver la relación de "clase" en la conciencia de la izquierda chilena, para ello Partidos políticos y movimiento obrero en Chile (1974, México: Ediciones Era), de Alan Angell. Para episodio muy referido, La Guerra Fría y la Ley Maldita (2009, Santiago: Debate), de Carlos Huneeus.

Sobre los "excedentes" y su vinculación con el cobre, Historia política del cobre 1945-2008 (2009, Santiago: Centro de Estudios Bicentenario), de Joaquín 
Fermandois, Jimena Bustos y María José Schneuer. De lo mucho que se ha escrito sobre las relaciones en Chile y EE.UU., un autor clásico es Paul Sigmund, con The United States and Democracy in Chile (1993, Baltimore: Johns Hopkins University Press).

Me disculparán los lectores si cito mucho mis textos, pero en ellos se encuentra una vasta literatura y fuentes acerca del tema. A pesar de los 35 años transcurridos desde su publicación, creo haber tratado detalladamente los temas aquí abordados en mi libro Chile y el Mundo 1970-1973. La Política Exterior del Gobierno de la Unidad Populary el Sistema Internacional (1985, Santiago: Ediciones Universidad Católica de Chile). Más orientado a la política interna, pero basado en material nuevo de archivos de la ex República Democrática Alemana y en otros archivos, está La revolución inconclusa. La izquierda chilena y el gobierno de la Unidad Popular (2013, Santiago: Centro de Estudios Públicos), donde también creo analizar con más material algunos aspectos de su política exterior y relaciones internacionales. Y otros textos de mi autoría son "¿Peón o actor? Chile en la Guerra Fría (1962-1973)” (primavera de 1998, Estudios Públicos, 72) y, en relación a los vínculos con EE.UU., "The persistence of a myth: Chile in the eye of the Cold War Hurricane" (invierno de 2005, World Affairs, 167[3]). Un importante libro sobre la historia internacional total de Allende y la Unidad Popular es El gobierno de Allende y la Guerra Fría Interamericana (2013, Santiago: Ediciones UDP), de Tanya Harmer. También, incluyendo material nuevo para entender al Chile internacional, está Historia de Chile 1960 - 2010. Tomo 5. Las vías chilenas al socialismo. El gobierno de Salvador Allende (1970-1973) Primera Parte (2019, Santiago: CEUSS), especialmente pp. 159-208 y 579-685, de Alejandro San Francisco (director general), José Manuel Castro, Milton Cortés, Myriam Duchens, Gonzalo Larios, Monserrat Risco, Alejandro San Francisco y Ángel Soto.

Las relaciones con Estados Unidos han sido enfocadas en tres libros recientes, que a su vez contienen gran parte o casi toda la bibliografía de valor que pueda existir. Me refiero a The Gathering Storm. Eduardo Frei's Revolution in Liberty and Chile's Cold War (2020, Ithaca-Londres: Cornell University Press) de Sebastián Hurtado-Torres; La elección presidencial de 1970. Pasado y futuro de un momento extraordinario (2020, Santiago: Editorial Historia Chilena), de Diego HurtadoTorres y Sebastián Hurtado-Torres; y Miradas desclasificadas. El Chile de Salvador Allende en los documentos estadounidenses (1969-1973) (2020, Santiago: UAH Ediciones), de Antonia Fonck.

Para las relaciones con Europa, "Del malestar al entusiasmo: la reacción de Bonn ante el gobierno de la Unidad Popular 1970-1973” (2008, Boletín de la Academia 
Chilena de la Historia, 117), de Joaquín Fermandois; ;Viva la verdadera amistad;: Franco y Allende, 1970-1973 (2014, Santiago: Editorial Universitaria), de María José Henríquez; De Franco a Pinochet. El proyecto cultural franquista en Chile, 1936-1980 (2006, Ediciones Departamento de Teoría de las Artes), de Isabel Jara; y Acuerdos y desacuerdos. La DC italiana y el PDC chileno: 1962-1973 (2015, Santiago: Fondo de Cultura Económica), de Raffaele Nocera.

Para las relaciones con el mundo socialista del bloque soviético y de Cuba, “¿Bajo el signo de Fidel? La Revolución Cubana y la 'nueva izquierda revolucionaria' chilena en los años 1960", de Eugenia Palieraki, en Chile y la Guerra Fría Global (2014, Santiago: RIL Editores), de Tanya Harmer y Alfredo Riquelme (eds.). También Vidas revolucionarias (2013, Santiago: Editorial Universitaria - Centro de Estudios Públicos), de Cristián Pérez; "Algunos aspectos de la ayuda financiera del Partido Comunista de la URSS al comunismo chileno durante la Guerra Fría” (1998, Estudios Públicos, 72), de Olga Ulianova y Eugenia Fediakova; y Die DDR und Chile. Aussenhandel und Solidarität (1960-1989) (2013, Berlín: CH. Links Verlag), de Inga Emmerling. 